Bol. Acad. peru. leng. 52. 2011 (165-180)

\title{
BAMBA
}

Carlos Arrizabalaga

Universidad de Piura

Fecha de recepción: $\quad$ 28/09/2011

Fecha de aceptación: $\quad$ 26/10/2011

"Si compras bamba, te quedas sin chamba": era el mensaje radiofónico que llamaba la atención en marzo del 2009, con dos peruanismos sonoramente tautovocálicos, sobre las consecuencias de la informalidad. Y es que esa cultura bamba "caracterizada por la falsedad de lo que se propone, produce y predica" 1 es nefasta para la economía nacional; también para la salud, por el peligro de panetones, vinos y chocolates bamba que llevarían a más de uno al hospital. Peor aún, hay medicinas bamba que matan, juguetes bamba tóxicos, munición bamba que explota, combustible bamba que te deja varado y lentes de sol bambas que producen ceguera.

También hay ternos bamba, cosméticos bamba, brevetes y títulos y certificados bamba de máster y doctorados bamba para profesores o contralores bambas... Por ahí vendían unos raticidas bamba que

1 Cfr. Dwight Ordóñez y Lorenzo Sousa. El capital ausente. De Toledo a Pachacutec, Lima: Club de Inversión, 2003, p. 160. 
engordaban a las ratas en lugar de matarlas. Y este "aluvión de tropelías informales", como decía Edgar Saba, ${ }^{2}$ aviva el ingenio hasta el punto que la prensa deportiva le decía "español bamba" a cierto entrenador de fútbol contagiado del dejo madrileño.

\section{La realidad bamba}

A veces son productos adulterados con envolturas idénticas al original, que en realidad no sirven para nada: pastillas hechas de yeso y colorante. Otras veces se trata de falsificaciones finalmente útiles como ropa, calzado, relojes, bolsos o pulseras, y para acertar si son de mejor o peor calidad hay que ser experto. En tercer lugar, están los que son de suyo productos bamba de marcas bamba, con lo que se quiere decir que resultan de pésima calidad: juguetes que duran cinco minutos, ropa que soporta solo un lavado... Se venden en huecos a la vista de todos, mercados populares que para unos son el paraíso, y para otros un vergonzoso peligro a punto de estallar.

Un reloj bamba es barato y se malogra al poco rato. Un libro pirateado es copia barata pero sirve igual, si no le falta alguna página. Lo contrario es el libro legal, el firme, calificación que recuerda al lema que sellaban en los viejos soles de plata: "Firme y feliz por la unión".

El mundo se convierte en un mercado sin ley en el que el consumidor escoge entre lo "firme" y lo "bamba". Algunos se vacilan del poder antideslizante de sus "caterpilar bamba", mientras otros se horrorizan. ¿Hay algo que no sea bamba? Se siente cierta impotencia, como si fuera natural esta "cultura bamba" o "cultura chicha" hecha de piratería y falsificación, "donde la versión pirata se torna verídica, donde el dedo deviene puré y lo que se imita aquiles se ofrece como lo que se fabrica ayala", como dice Julio Hevia. ${ }^{3}$ ¿Muestra genuina de creatividad e ingenio, o cierta inclinación heredada hacia el engaño?

2 "La Noticia Bamba" en Caretas, 08/01/1998.

3 iHabla, jugador! Gajes y oficios de la jerga peruana, Lima: Taurus, 2008, p. 13. 
No hay que improvisar conclusiones definitivas, porque en todas partes se cuecen habas.

También se "bambea" el combustible cuando le echan agua. "Todo Lima bambea la gasolina", declaraba uno. Ante supuestas "cortinas de humo" un comentarista denunciaba que algunos "bambean" el periodismo. Otros presentan papeles bamba en su currículum, y así Mirko Lauer sugería la conveniencia de una empresa privada dedicada a verificar la validez de los títulos, y de la misma exactitud de las calificaciones. Serviría mucho a los empleadores, y también a los profesionales dentro y fuera del Perú. ${ }^{4}$

Alcanza también al ámbito político y al mundo judicial. En el juicio a Alberto Fujimori se hablaba de testigos bamba. Se habla también de un modelo económico "bamba" para el Perú, con un liberalismo bamba, un socialismo bamba... ${ }^{6}$ También desde las ciencias sociales, tan proclives a inventar conceptos, se ha creado el sustantivo "bambeo" a imitación y por una forzada correspondencia con "huaqueo", con la presunción de que el discurso académico falsea la identidad histórica de un pueblo. ${ }^{7}$ Finalmente, el término recibe las acepciones de 'falso', 'adulterado', 'acomodado a un interés particular' o también 'acomodado al modo informal'.

\section{Léxico de la informalidad}

"Bamba" es una palabra reciente y ello indica que la informalidad no abarcaba tantos aspectos de la vida cotidiana antes de los años setenta. Tal vez el primero en utilizar el término en el sentido más actual fue Edgardo Rivera Martínez, en 1977, al referirse a los “jeans” que se hacían

4 Mirko Lauer. "Máster bamba", El Comercio, 27/03/2009.

5 El Comercio, edición digital, 16/02/08.

6 Ramiro Valdivia Cano. Las elecciones en el Perú. Lima: J.C. Servicios Gráficos 1998, p. 15.

7 Sin ser especialista en la materia, no veo sustento suficiente para justificar la creación de dicho concepto ni las consecuencias que se le derivan. Cfr. Dorian Espezúa Salmón. "Huaquear y bambear", Identidades, Suplemento cultural de El Peruano, Lima, 10 de marzo de 2003 , pp. $5-7$. 
en San Cosme o Gamarra con marcas en inglés, por cierto, productos "bamba" de una incipiente industria textil nacional. ${ }^{8}$

Tramposos hay en todas partes. Concolorcorvo se burlaba en 1775: "En todo hay trampa menos en la leche, que le echan agua y a veces se halla un bagrecillo que la manifiesta", denunciando también que el contrabando de bayetas inglesas a precio ínfimo llevó a la quiebra a los obrajes cuzqueños.?

Sin embargo, creo que el desorden generado en la dictadura militar (1968-1976) propició la proliferación de la informalidad como solución de emergencia para la economía peruana. Los tiempos de crisis se superan y el país busca retomar canales formales y criterios técnicos en su vida institucional, por lo menos hasta niveles mínimamente aceptables. El Perú se formaliza y lo "bamba" nos viene ahora de China o de quién sabe dónde.

La tentación de resolverlo todo por la vía informal del engaño y la improvisación que tuguriza los mercados o contamina costa, sierra y selva con mineras bamba no da buenos resultados a mediano y largo plazo. Se han señalado razones respecto a que la cultura bamba surge del subempleo y el analfabetismo, e incluso de la infravaloración que se hace de lo propio. También es un efecto de esta idolatría del consumismo que obliga a todos a comprar lo que sea como sea a como dé lugar. Y está en consonancia con un fenómeno de incoherencia personal y esquizofrenia social que suele conocerse como "achoramiento", en el que la credibilidad y la confianza en las normas se reemplazan por una actitud pragmática que considera la posibilidad de transgredirlas si con ello se alcanza algún propósito. ${ }^{10}$

8 “¿Un país para extranjeros?” en Estampas de ocio, buen humor y reflexión, Lima: Universidad Nacional Mayor de San Marcos, 2003, pp. 203-205. Originalmente publicado en el diario Correo, el 13 de diciembre de 1977.

9 Alonso Carrió de la Vandera (= Concolorcorvo). Lazarillo de ciegos caminantes. Edición de Emilio Carilla, Barcelona: Labor, 1973, p. 355.

10 Oswaldo Medina. "La cultura del achoramiento, nueva estrategia para el ascenso social", en El achoramiento, una interpretación sociológica, Lima: Universidad del Pacífico, 2001, p. 46. 
El imperio de la informalidad también se pone de manifiesto en otras expresiones surgidas todas en el ámbito coloquial y no solo del hampa, aunque esta es una fuente importante del mismo, como puso de relieve José Bonilla Amado. ${ }^{11}$ Así pues, un respeto simulado a la norma se suele indicar como "un saludo a la bandera" o las artimañas por las que se evade el control de la ley, se conoce como "sacarle le vuelta" o "hacer la finta". A falta de trabajo formal, buenos son los "cachuelos" que salen por ahí. Otra expresión frecuente es "la mecida" con que se espera que los asuntos prescriban o, simplemente, la persona o institución agraviadas se cansen de esperar y finalmente se olviden del reclamo, lo que también se conoce como "hacerla larga".

En el español peruano hay pues un buen número de expresiones de este rico campo léxico de la informalidad, como pagar "festinación", "derecho de piso", "pisar el palito", "criollada", y "trafa” que parece acortamiento humorístico de "tráfago" o "estrafalario", pero más supongo que vendrá de "tráfico" o "traficante". Y el soborno se conoce popularmente como "coima", palabra que en la jerga del siglo XVII significaba 'prostituta'. Todo este léxico mantiene una estrecha relación, y va ganando terreno en otros ámbitos, aunque el origen puede ser muy turbio, como el caso de "faenón", recientemente difundido, que no es más que un superlativo lexicalizado.

\section{Pesquisas lexicográficas}

La palabra "bamba" en español es una voz onomatopéyica con cinco acepciones: 'acierto', 'bollo de crema', 'ritmo bailable', 'baile que se ejecuta con ese ritmo' y en Cuba, 'andamio'. También era el nombre de una marca peninsular de zapatillas entre los años 60 y 70 , y de ahí sigue llamándose bambas a un tipo de zapatillas de lona con suela de goma.

11 Ver José Bonilla Amado. Jerga del hampa. Lima: Editorial Nuevos Rumbos, 1956. Ver ahora Paola Arana Vera, "Breve vocabulario de replana limeña", en Actas del III Congreso Internacional de Lexicología y Lexicografía en homenaje a Diego de Villegas y Quevedo Saavedra, Lima: Academia Peruana de la Lengua, 2009, pp. 99-107. 
Cejador y Frauca señala que en el Siglo de Oro bamba "es apodo de boba entonada y melindrosa, aludiendo a baba, aplícase a personas para poco y alas entonadas que no hay quien les diga nada." ${ }^{12}$ Corominas considera que la acepción de 'bobo' es creación expresiva de principios del siglo XVII, y la vincula con bambalina y bambalear. ${ }^{13}$

Los diccionarios de americanismos registran la acepción de 'moneda de plata' como usual hasta mediados del siglo XX en Centroamérica y Venezuela. Marcos Augusto Morínigo registra además para Guatemala el derivado "bambita" con el significado de 'pequeña moneda de plata'. ${ }^{14}$ Con esta acepción también lo recoge Renaud Richard sin atender a que la palabra ya está en desuso. ${ }^{15}$ En Costa Rica era una moneda grande de oro, según Miguel Ángel Quesada Pacheco. ${ }^{16}$ Necesitamos contar con más diccionarios históricos para reconstruir con mayor fidelidad la historia léxica de Hispanoamérica, pero es posible imaginar que la extensión del término provino de las Islas Canarias en el siglo XVIII, pues no se registra en el siglo anterior, en el que la moneda de bajo cuño se conocía como "reales de lata" o "reales sencillos". ${ }^{17}$

La Real Academia acogió con la marca "coloquial", y en una entrada independiente, la incorporación de "bamba" y "bambear", según la propuesta elevada en septiembre de 2000 por la Comisión de Lexicografía de la Academia Peruana de la Lengua, que fue constituida en marzo de ese mismo año por los investigadores Augusto Alcocer, Marco

12 Julio Cejador y Frauca. Diccionario fraseológico del Siglo de Oro: (fraseología o estilística castellana). Edición de Abraham Madroñal y Delfín Carbonell. Barcelona: Serbal, 2008, p. 71.

13 Joan Corominas y J. A. Pascual. Diccionario crítico etimológico castellano e hispánico. Madrid: Gredos, 1991, vol. II, p. 483.

14 Marcos Augusto Morínigo. Diccionario de Americanismos, Buenos Aires: Muchnik, 1966, p. 85.

15 Richard Renaud (dir.). Diccionario de hispanoamericanismos no recogidos por la Real Academia. Madrid: Cátedra, 2006, p. 67.

16 Diccionario histórico del español de Costa Rica, San José: EUNED, 1995, p. 11.

17 Ver ejemplos en Elvira Ramos y Adriana Quinter. "Léxico del español colonial venezolano en testamentos merideños del siglo XVII. Una evaluación del corpus." Actas del II Congreso Internacional de Lexicología y Lexicografía en homenaje a Pedro Benvenutto Murrieta, Lima: Academia Peruana de la Lengua, 2008, pp. 417-432. 
Ferrell, Luis Andrade, Ana Baldoceda y Luisa Portilla, bajo la dirección de Rodolfo Cerrón-Palomino: ${ }^{18}$

bamba. adj. invar. Perú. coloq. Falso, adulterado. Decomisaron medicamentos BAMBA. Ú. t. c. s. ${ }^{19}$

Sigue las breves acepciones que había registrado Juan Álvarez Vita en 1990:

Bamba adj. fam. Adulterado.

Bambear. fam. 'adulterar'. ${ }^{20}$

Julio Calvo cree que este "bamba" tiene también un componente onomatopéyico no exento de carácter humorístico. ${ }^{21}$ La repetición es usual en las expresiones peyorativas, y el efecto tautovocálico es un recurso muy usual en el léxico popular, pero la palabra tiene una historia -como suele ocurrir- bastante complicada, y no parece tratarse de una creación espontánea reciente, sino de una voz con una larga trayectoria histórica.

Su registro más temprano está en un pequeño vocabulario de jerga criolla recogido por el oficial de policía Rafael Bastos Samaniego en 1957, quien consigna simplemente "bamba: anillo". ${ }^{22}$ Más cerca

18 Ana Baldoceda. "Resultados de la propuesta lexicográfica peruana en el diccionario de la Real Academia". Boletín de la Academia Peruana de la Lengua, 36, 2002, pp. 85-162.

19 Luisa Portilla. "Enmiendas y adiciones a la vigésima segunda edición del Diccionario de la Real Academia de la Lengua Española: La propuesta peruana”. Lengua y sociedad. Instituto de Investigaciones de Lingüística Aplicada de la Universidad Nacional Mayor de San Marcos, 4, 2002, pp. 49-61, especialmente p. 52.

20 Juan Álvarez Vita. Diccionario de peruanismos. Lima: Studium, 1990, p. 77. En la segunda edición amplía un poco las acepciones: "Bamba. 'falso, adulterado'." "Bambear. 'adulterar un producto o venderlo con falsa presentación'." Diccionario de peruanismos. El habla castellana del Perú. Lima: Academia Peruana de la Lengua y Universidad Alas Peruanas, 2009, pp. 85-86.

21 Diccionario Español-Quechua/Quechua-Español. Lima: Universidad San Martín de Porres, 2009.

22 Argot, Jerga o Caló. Lima: Talleres Gráficos P. L. Villanueva. El investigador José Antonio Salas me ha proporcionado esta referencia que me era desconocida. No está recogido en la Jerga del hampa de José Bonilla Amado (1956). Lima: Editorial Nuevos Rumbos, 1957. Cfr. Paola Arana Vera, Jerga del hampa de José Bonilla Amado en el castellano actual li-

Bol. Acad. peru. leng. 52(52), 2011 
de la acepción que nos ocupa, aparece en el léxico de Foley Gambeta, quien menciona "bamba" como término de replana: "alhaja falsa que se pretende pasar por como legítima", o "cualquier joya de fantasía, en particular la sortija." 23

Fedor Larco Degregori recoge ahora las acepciones de "falso, engañoso, fingido, simulado, falto de ley, de realidad o veracidad”, y añade una segunda acepción que parece más que nada una explicación de la primera: "dícese de los objetos que con intención delictiva se hacen imitando a los legítimos". Recoge también el adjetivo "bambeado" con las acepciones de 'robado', 'adulterado' y su variante humorística "bambarén”, y el verbo "bambear” con tres acepciones: 'estafar', 'lucrar mediante el engaño o abuso de confianza', y 'hurtar'. Por último es el único que recoge un derivado colectivo: "bambería. Joyas falsas, de fantasía." ${ }^{24}$ También Álvarez Vita parece estar conforme con la idea de que el término "originariamente se usó para designar a cualquier joya de fantasía, principalmente a las sortijas". ${ }^{25}$

Por su parte, Antonio Gálvez Ronceros, en los años setenta mencionaba que "puro bamba" era equivalente a expresiones cubanas como "tremendo globo" o "tremenda guayaba", con el significado de 'embuste'. ${ }^{26}$ Martha Hildebrandt señala en una nota periodística que "bamba" parece proceder de Colombia, Venezuela o las Antillas. Era también usual en Costa Rica, Nicaragua y Honduras, países en los que se conocía como "bambas" a las monedas de un peso, herederas de

meño", Mnemósine, 2, 2009, p. 8. No lo registra tampoco Luisa Portilla Durand en Léxico peruano. Español de Lima. Lima: Universidad San Martín de Porres, 2008.

23 Enrique Foley Gambetta. Léxico del Perú: Diccionario de peruanismos, replana criolla, jerga del hampa, regionalismos y provincialismos del Perú. Lima: Talls. de Jahnos, 1983. Son ocho fascículos que fueron hechos con recursos propios del autor; cubren hasta la letra Ch y abarcan alrededor de 7800 entradas. Agradezco especialmente a Eder Peña por la amabilidad de haberme facilitado esta información y por brindarme también la indicación anterior.

24 Fedor Larco Degregori. Diccionario de Jeringa Peruana, Lima: Publicidad Causa, 2000, p. 30.

25 Diccionario de peruanismos. El habla castellana del Perú, p. 85.

26 Antonio Gálvez Ronceros. "Voces y dichos populares. El habla cubana", incluido ahora como "Habla popular peruana y cubana" en Aventuras en el Candor. Lima: Editorial Extramuros, 1989, pp. 53-61. La referencia está en p. 59. 
los antiguos reales canarios. ${ }^{27}$ De ahí también se debe explicar la frase negativa "ni bamba" que era usual en Colombia: madera!" 28

"iSi no fuera por eso, ni bamba de trabajar en esa nada de

\section{Las monedas bambas canarias}

El término tiene en España antecedentes muy ligados al comercio con las Indias. En el siglo XVIII, en las Islas Canarias, se falsificaron a gran escala unas monedas de plata que llamaban "bambas" por decir que eran antiguas. Los reales "bambas" inundaron las transacciones, al punto que -medio siglo después- Carlos III tuvo que ordenar la extinción de todas las monedas acuñadas en las islas, ya fueran firmes o bambas.

Todavía hoy los canarios acostumbran a llamar "godos" a todos los peninsulares. $\mathrm{Y}$ así esas monedas antiguas, ya muy gastadas, en su mayor parte fueron vueltas a acuñar con otra ley por los mismos plateros canarios. Para cuando el rey ordenó que se retirasen todos esos "reales bambas", como la mayoría eran falsos, el nombre propio de las monedas, gentilicio familiar en las islas, terminó otorgando ese contenido calificativo a la pieza de pequeño valor o falsa.

En efecto, en Canarias además de los pesos fuertes de América y los tostones de Portugal habían corrido siempre con abundancia ciertos reales y medio reales de plata de dos o tres especies de cuño, y los que se usaron durante el reinado de los Reyes Católicos allí los llamaban bambas y tenían por sello un haz de saetas y al reverso una coyunda con los nombres de Isabel y Fernando. En la Península se dieron por inútiles desde 1726 y se llevaron a las Islas, donde evidentemente había menos control monetario. El historiador del siglo XIX José de Viera

27 Cfr. Miguel Á. Quesada Pacheco. Diccionario histórico de Costa Rica. San José: EUNED, 1995 , p. 11.

28 Tomás Carrasquilla. La marquesa de Yolombó (1928). Ed. Kurt L. Levy, Caracas: Biblioteca Ayacucho, 1984, p. 116.

Bol. Acad. peru. leng. 52(52), 2011 
y Clavijo refiere que hacia 1720 "se notó que los realillos de mala ley inundaban enteramente el comercio", pues de una onza de plata sacaban los monederos treinta y cinco y a veces cuarenta reales corrientes, y así pues mientras los superiores disimulaban o dormían "los fabricantes de bambas abundaron". ${ }^{29}$

Esos realillos contrahechos y sin el peso correspondiente pasaban de mano en mano hasta que en 1734 un holandés denunció "que los reales bambas con que querían pagarle eran falsos y que semejante moneda no valía". Con ello también la renta del tabaco se veía perjudicada, ${ }^{30}$ por lo que salió un edicto ordenando que "se manifestase en la tesorería real de La Laguna toda la moneda bamba que cada uno tuviese (...) se cortase la falsa (estuviese o no resellada) y se volviese con la moneda legítima a sus dueños". Los plateros aprovecharon la oportunidad para quedarse con el $10 \%$ del valor y ante la amenaza de perder ahí sus haberes muchos optaron por esconder sus monedas antes de bajar a resellarlas. El 20 de abril de 1776 Carlos III firma una pragmática extinguiendo las monedas antiguas y peculiares

"que han corrido en las Islas Canarias bajo del nombre común de fiscas y bambas, que se daba a las islas a su antigua moneda". ${ }^{31}$

No hay que olvidar que las Islas Canarias, en la vía de Sevilla a Cartagena y la Habana, constituyeron un importante puente lingüístico entre dos mundos gracias al comercio y las migraciones. ${ }^{32}$

29 José de Viera y Clavijo. Noticias de la historia general de las Islas de Canaria: contienen la descripción geográfica de todas: una idea del origen, carácter, usos y costumbres de sus antiguos babitantes: de los descubrimientos, y conquistas que sobre ellas bicieron los Europeos: de su gobierno eclesiástico, político... Impr. y Litografía Isleña de J.N. Romero, 1863, tomo IV, p. 369.

30 Aunque señala Viera y Clavijo que "fue la causa el hallarse el obispo y otros muchos personajes de islas con muchos miles de pesos en reales bambas", ibid., p. 370.

31 Colección de pragmáticas, cédulas, provisiones, autos acordados, y otras providencias generales expedidas por el Consejo Real en el reynado del Señor Don Carlos III: cuy a observancia corresponde á los tribunales y jueces ordinarios del reyno, y á todos los vasallos en general. Madrid: Viuda e hijo de Marín, 1803, p. 329.

32 Ver Manuel Alvar. "Canarias en el camino de las Indias", en España y América cara a cara, Valencia: Editorial Bello, 1975, pp. 9-48. 


\section{Bambas por antiguas}

La razón por la que los canarios llamaban "bambas" a las monedas disfrazadas de viejas es la que llevaba a Juan del Valle y Caviedes, en Diente del Parnaso, a decir que un médico único en Lima se había curado "de un pestífero contagio", que no es otro que el "mal de pobre" porque:
"Casóse con una vieja
más antigua que Velazco,
que al rey Wamba no le dejó
nada en materia de años.
Viuda era de un panadero
Y con Pico se ha velado,
Con él gastará sirviendo
Lo que otro ganó amasando."33

Porque los panaderos eran (y son todavía) personas de buena posición. Igual se decía del tiempo de los godos como de Maricastaña o de Nangué, ${ }^{34}$ sin saber quiénes pudieran haber sido. Los canarios llaman todavía hoy "godos" a todos los peninsulares, como era usual en América, y así llamaban "reales bambas" a los acuñados en tiempos de los Reyes Católicos, ya muy gastadas y en su mayor parte vueltos a acuñar con otra ley por los avispados plateros canarios, aunque Ambrosio de Morales, cronista de Felipe II, afirmaba haber visto todavía, en el siglo XVI, dos monedas de oro del rey Bamba:

"Su verdadero nombre no es Bamba, como corrompiendo el vocablo comúnmente pronunciamos, sino Wamba, como parece en dos monedas suyas que yo he visto; y tienen aún más muestras de cristiandad y devoción que suele haber en las otras monedas góticas. Su rostro de la una parte es diferente de los ordinarios que

\footnotetext{
33 Juan del Valle y Caviedes. "Casamiento de Pico de Oro con una panadera vieja, viuda y rica”, en Obras. Ed. Rubén Vargas Ugarte, Lima: Clásicos Peruanos, 1947, pp. 266-268.

34 Rubén Vargas Ugarte. Glosario de peruanismos, Lima, 1953, p. 74.
} 
vemos en tales monedas: pues con los ojos alzados está mirando con atención una cruz, parece tenerla en la mano. Al derredor dicen las letras WAMBA. REX." 35

\section{El legendario rey Wamba, (o Bamba)}

Sucesor de Recesvinto en la España visigoda, se contaban de él "tantas fábulas que aun no será menester contradecirlas - dice Ambrosio de Morales-, según ellas son vanas y desvariadas". ${ }^{36}$ Así es mencionado dos veces en el Quijote, sacado «de entre los bueyes, arados y coyundas para ser rey de España» (II, 33). Juan de Timoneda había incluido en su Rosa gentil (1573), un romance que puede muy bien ser de su autoría, en el que relataba que luego de muchas disputas entre los godos, un ángel manifiesta:

"que el rey que ellos esperaban, su nombre Bamba sería y lo habían de hallar arando cerca de la Andalucía". ${ }^{37}$

El lugar estaba en Portugal, entonces unida a España en la persona de Felipe II, por lo que resultaba una figura ejemplar, con claras alusiones bíblicas, y prueba además de la divina Providencia:

En el tiempo de los Godos, que en Castilla rey no había, cada cual quiere ser rey aunque le cueste la vida. ${ }^{38}$

\footnotetext{
35 Crónica General de España. Madrid: Benito Cano, 1791, tomo VI, p. 237.

36 Crónica General, p. 238.

37 "Romance del Rey Bamba", en Rosa de romances. Romances sacados de las Rosas de Juan Timoneda, que pueden servir de suplemento á todos los romanceros, asi antiguos como modernos $y$ especialmente al publicado por el señor don G. B. Depping, escogidos, ordenados y anotados por don Fernando José Wolf. Leipsique: F. A. Brockhaus, 1846, pp. 3-4.

"Romance del Rey Bamba", ibidem.
} 
Disputaban por quién fuera el siguiente rey y san León papa les indicó que el escogido era Bamba, un noble godo que vivía olvidado de todo en Hircania, (actual Portugal), arando sus tierras, tan feliz con sus dos bueyes como presentará luego Stevenson al viejo arquero Appleyard con sus coles, en La flecha negra (1888).

Lope de Vega compuso con esta historia una de sus primeras comedias, titulada justamente $\mathrm{El}$ Rey Bamba, ${ }^{39}$ en que añade algunos episodios imaginativos a la historia principal, junto con los antecedentes que explican la ulterior traición del ambicioso Ervigio. El tema no vuelve a aparecer hasta que en la España renacentista Zorrilla pone a Bamba como protagonista de El Rey loco, drama de los más olvidados de su repertorio. ${ }^{40}$

Cervantes pudo leer la fantasiosa Historia de los Reyes Godos que vinieron de la Escitia de Europa, de Julián del Castillo (1582), pero tanto Timoneda como Lope de Vega toman como fuente Valerio de las Historias Escolásticas y de España (1487), recopilación hecha al modo de Valerio Máximo, con gran número de hechos y dichos memorables, y entre ellos muchas anécdotas de la historia nacional. Su autor, el arcipreste de Santibáñez, Diego Rodríguez de Almela, natural de Murcia, fue un fecundo compilador histórico del tiempo de la Reina Católica, capellán y cronista suyo. Esta obra, muy popular durante todo el XVI, trae en el título cuarto del libro III, que trata de aquellos que nacidos de baxo lugar fueron fechos claros y nobles, un capítulo entero, sobre el Rey Vamba, el único que aparte del rey Rodrigo ha dejado una estela de leyendas en la cultura hispana. El romance de Timoneda es casi una mera versificación del texto del Valerio y varios pasajes de la comedia lopesca están "calcados con rara

39 Lope de Vega la dio a la imprenta, en 1604, en un volumen que incluye también "El cerco de Santafé" y el drama de Bernardo del Carpio, inspiración de muchas dramatizaciones populares en Hispanoamérica. Se publicó en la Primera parte de las comedias de Lope (Valencia, 1604), reimpresa hasta nueve veces aquel mismo año y cinco veces más en otras ciudades. Cfr. Menéndez Pelayo. Estudios sobre el teatro de Lope de Vega, Santander: Consejo Superior de Investigaciones Científicas, 1949, tomo III, p.8.

40 Cfr. Menéndez Pelayo. Estudios sobre el teatro... p. 29.

Bol. Acad. peru. leng. 52(52), 2011 
habilidad", señala Menéndez Pelayo, del romance de Timoneda, cuyos primeros versos se repiten a la letra:

"En el tiempo de los godos,

Que no había Rey en Castilla,

Cada cual quiere ser Rey

Aunque le cueste la vida." ${ }^{11}$

La popularidad de estos textos bien habría podido incidir en que los canarios llamaran "bambas" a las monedas antiguas, puesto que en ellos se mencionan las monedas antiguas monedas de Wamba: "Por él está la coyunda / puesta en reales de Castilla”, dice el romance. ${ }^{42}$

El nombre del "buen rey Bamba" se relacionaba además con varias frases del folklore español: "viven en Bamba" se decía de los tontos, o "caballito de Bamba", a los displicentes. ${ }^{43}$ En una comedia de Calderón de la Barca se dice de un enamorado que "ni anda ni come ni bebe, / como el caballo de Bamba".44

También en la última novela picaresca, La vida $y$ hechos de Estebanillo González se cuenta que a la quiebra de un "vivandero" nadie quería llevarse en el remate un viejísimo rocín que parecía "caballito de Bamba". ${ }^{45} \mathrm{Y}$ en otra comedia de Tirso de Molina también se lamenta un criado del enamoramiento de su señor:

"Pero ique tenga yo un amo en menudos, como el macho de Vamba, que ni manda, ni duerme, come o bebe, y siempre anda!" 46

41 Cfr. Marcelino Menéndez Pidal. Estudios sobre el teatro..., pp. 17-30.

42 En el romance Bamba tira de dos bueyes uno blanco y otro prieto. En la comedia de Lope (y en el Valerio) uno es rojo y otro blanco.

43 Cfr. Julio Cejador y Frauca. Diccionario... p. 71.

44 "También hay duelo en las damas", en Juan Jorge Keil, Las comedias de D. Pedro Calderón de la Barca cotejadas con las mejores ediciones hasta abora publicadas, Leipsique: Ernesto Fleischer, 1828, tomo II, p. 213.

45 Madrid: Cátedra, Ed. A. Carreira y J. A. Cid, 1990, vol. II, p. 35.

46 Don Gil de las calzas verdes, Edición de Alonso Zamora Vicente, Madrid: Castalia, p. 262. 
El rey Bamba siguió siendo una referencia cada vez menos frecuente y más vaga. Bolívar comparó al general La Mar, que aborrecía el poder, con Bamba "que prefería morir a tomar el trono". ${ }^{47}$

\section{Conclusión}

Ahora decimos bambas a panetones y medicinas peores que monedas falsas. Todavía se resiste a la concordancia: "¿juguetes bamba o bambas?", y es que la palabra fue nombre propio y término común antes de convertirse, en el Perú, en ingenioso calificativo de la informalidad.

En el idioma ha habido otros términos para significar lo que no tiene el valor que le corresponde. Así, en el siglo XIX se extendieron monedas falsas procedentes de Bolivia que se conocieron como "pesos febles", por decir "débiles" o de poco valor, porque mezclaban plata con cobre, particularmente en los tiempos de la confederación. ${ }^{48}$

Es posible pensar que la profusión de pequeñas alhajas (collares, pulseras, anillos) aprovechando pequeñas monedas antiguas de plata facilitó el traslado del término "bamba" del ámbito numismático al del mercadeo, adquiriendo o tal vez trasmitiendo la acepción de 'falsa' o 'de baja ley' a las joyas que se vendían por encima de su real valor, hasta que finalmente el significado de 'adulterado' se extendió a todo el mundo del comercio y de ahí a otros ámbitos. Al menos en las acepciones que ofrecen Foley Gambetta y Fedor Larco estaban presentes dos aplicaciones del término a la joyería de bajo valor.

Nos queda por resolver si del mismo origen de este "bamba" peruano, puede venir también el nombre de un baile mexicano con algo de trescientos años de antigüedad, que cuenta ya con más de doscientas versiones, aunque la más conocida es esa que dice: "Para bailar la bamba

47 Cfr. Jorge Basadre. Historia del Perú Republicano, Lima: Universitaria, 1983, tomo I, p. 105.

48 Cfr. Antonio Garland. Estudio sobre los medios circulantes usados en el Perú, Lima: La Industria, 1908.

Bol. Acad. peru. leng. 52(52), 2011 
se necesita una poca de gracia..." Pero no sería extraño que en sus inicios hubiera sido una danza de tipo dramático que hubiera querido representar de algún modo el argumento de la comedia lopesca, igual que en zonas rurales del Perú como en San Lucas de Colán, en la provincia de Piura, o San José en Lambayeque, se desarrollaron danzas de Bernardo del Carpio o de moros y cristianos, y otras similares, cuyos argumentos se difundieron en la misma edición de 1604 .

\section{Correspondencia:}

Carlos Arrizabalaga

Profesor de la Universidad de Piura.

Correo electrónico: carlos.arrizabalaga@udep.pe 